\title{
Correction to: Innovativeness: a bibliometric vision of the conceptual and intellectual structures and the past and future research directions
}

\section{Danilo Magno Marchiori ${ }^{1,2}$ (D) Silvio Popadiuk ${ }^{2} \cdot$ Emerson Wagner Mainardes $^{3}$. Ricardo Gouveia Rodrigues ${ }^{1}$}

Published online: 19 April 2021

(c) Akadémiai Kiadó, Budapest, Hungary 2021

\section{Correction to: Scientometrics (2021) 126:55-92 https://doi.org/10.1007/s11192-020-03753-6}

In the original publication of the article the authors' affiliations were incorrectly published and the Acknowledgements section was not included. These have been corrected with this Correction.

Acknowledgements The authors would like to thank to NECE-UBI-Research Unit for Business Sciences funded by the Multiannual Funding Program of R\&D Centers of FCT-Foundation for Science and Technology, under the project UIDB/04630/2020.

The original article can be found online at https://doi.org/10.1007/s11192-020-03753-6.

Danilo Magno Marchiori

danilo.marchiori@gmail.com

1 University of Beira Interior/NECE, Covilhã, Portugal

2 Mackenzie Presbiterian University, São Paulo, Brazil

3 Fucape Business School, Vitória, Brazil 